\title{
Overcoming the learning curve of single-port total laparoscopic hysterectomy with barbed suture: a single surgeon's initial experience
}

\author{
Yoon Hee Lee, Gun Oh Chong, Mi Ju Kim, Dae Gy Hong, Yoon Soon Lee \\ Department of Obstetrics and Gynecology, School of Medicine, Kyungpook National University Medical Center, Daegu, Korea
}

Videosurgery Miniinv 2017; 12 (3): 264-270

DOI: https://doi.org/10.5114/wiitm.2017.68106

\begin{abstract}
Introduction: Single-port total laparoscopic hysterectomy (TLH) has not been widely used because of its technical difficulty and steep learning curve, especially the laparoscopic suturing of the vaginal stump. Barbed suturing is a new technology that has the potential to greatly facilitate laparoscopic suturing.

Aim: To compare surgical outcomes and vaginal vault healing between barbed sutures and traditional sutures in the repair of the vaginal vault during single-port $T L H$.

Material and methods: Between August 2013 and June 2015, we performed single-port TLH in 85 consecutive patients for benign or premalignant gynecological conditions. The first 48 patients underwent single-port TLH with traditional interrupted sutures, and the next 37 patients underwent single-port TLH with absorbable unidirectional knotless barbed sutures for repair of the vaginal vault.

Results: The patient characteristics (age, body mass index), procedures performed, uterine weight, and uterine disease were similar between the groups. There were no differences in blood loss, hemoglobin change, length of hospital stay, or perioperative complications. Operative time and the time required for vaginal cuff suturing were significantly shorter in the barbed suture group than in the traditional suture group (57.8 $\pm 13.5 \mathrm{vs} .80 .1 \pm 18.7 \mathrm{~min}, p<0.001$; $5.5 \pm 1.7$ vs. $12.9 \pm 3.5 \mathrm{~min}, p<0.001)$. Moreover, the use of barbed sutures significantly reduced the incidence of vaginal granulation tissue formation (2.7\% vs. $35.4 \%, p<0.001)$.

Conclusions: Use of barbed sutures in single-port TLH reduced the operative time, suturing time of the vaginal vault, and formation of vaginal granulation tissue. Barbed suturing may help overcome surgical difficulties and vaginal cuff complications.
\end{abstract}

Key words: single-port, total laparoscopic hysterectomy, barbed suture, surgical outcomes, vaginal vault complication.

\section{Introduction}

Compared with laparotomy, the laparoscopic approach for hysterectomy offers the potential benefit of decreased patient discomfort, shorter hospital stay, superior cosmetic results, and decreased convalescence time [1]. At present, the laparoscopic route is becoming a more popular type of hysterectomy, from $0.3 \%$ in 1990 to $12 \%$ in 2003, with steadily growing rates. Recently, single-port surgery was introduced to maximize the benefits of laparoscopic procedures, including reduction in the size and number of ports. However, single-port total laparoscopic hysterectomy $(\mathrm{TLH})$ has not been widely used because of its technical difficulty and steep learning curve, especially the laparoscopic suturing of the vaginal stump. In our previous study, the

\section{Address for correspondence}

Gun Oh Chong MD, PhD, Kyungpook National University Medical Center, 807 Hogukno, Buk-gu, 702-210, Daegu, Korea,

phone: +82 53200 2684, +82 103060 5356, fax: +82 53200 2028, e-mail: gochong@knu.ac.kr 
mean operative time and time for vaginal stump repair in single-port TLH were significantly longer than those in conventional TLH [2].

The rate of postoperative vaginal vault complications after laparoscopic hysterectomy has been reported to be $0-5 \%[3,4]$. Vaginal vault granulation is a common postoperative complication after hysterectomy. Its clinical presentations include vaginal discharge, abnormal vaginal bleeding, and postcoital bleeding. The incidence of vaginal vault granulation after abdominal hysterectomy was reported to be from $3.1 \%$ to $34 \%$ [5-7]. However, the incidence of vaginal vault granulation after laparoscopic hysterectomy has not been reported.

Knotless barbed sutures are an innovative suturing material that can facilitate laparoscopic operations. One of these novel sutures is V-Loc (Covidien, Mansfield, MA, USA), which consists of a unidirectional barbed absorbable thread equipped with a surgical needle at one end and a loop at the opposite end to secure the suture. The barb and loop ends enable approximation of tissue without the need to tie a surgical knot. Recently, several studies have reported that barbed sutures reduced the operative time, vaginal cuff dehiscence, and postoperative vaginal bleeding in laparoscopic hysterectomy [4, 8-10]. To date, however, only minimal data on the use of barbed sutures during single-port TLH are available.

\section{Aim}

The purpose of this study was to compare the perioperative outcomes and postoperative vaginal vault complications between barbed sutures and traditional sutures and to evaluate the effect of barbed sutures on the learning curve of single-port TLH.

\section{Material and methods}

\section{Patients}

All patients signed a written informed consent form before single-port TLH, and data were collected prospectively after institutional review board approval.

The eligibility criteria for the patients were as follows: age 20 years or older, no evidence of gynecological malignancy on imaging studies, an appropriate medical status for laparoscopic surgery, and uterine size of $\leq 1000 \mathrm{~g}$ as determined with preoperative pelvic ultrasound examination. The exclusion criteria were a uterine size of > 1000 g according to preoperative pelvic ultrasound, suspected gynecological cancer, and more than three prior laparotomies. All operations were performed by a single surgeon (G.O.C.). Clinical follow-up was performed at 2 weeks, 1 month, 2 months, and 5 months after the operation, and vaginal vault complications and other postoperative complications were evaluated.

\section{Surgical procedures}

For single-port TLH, we used an Octoport (Dalim, Seoul, Korea). A vertical, transumbilical incision of 25-30 mm length was made that extended to the peritoneum. The abdominal wall was elevated using Army-Navy retractors that were inserted into the opening of the incision. The Octoport wound retractor $(30 \mathrm{~mm})$ was placed into the peritoneal cavity covering from the skin to the peritoneum. The Octoport has three access ports (one 12-mm port and two 5-mm ports), and an additional gas inlet and gas outlet (Photo 1). We used a rigid, 30, 10-mm laparoscope (Stryker, San Jose, CA, USA) and standard rigid instruments. The round ligaments, ovarian ligaments, and broad ligaments were dissected with a LigaSure system (Covidien, Valleylab, Boulder, CO, USA). The vesicouterine peritoneal fold was opened, and the bladder was mobilized with a monopolar coagulator. The uterine vessels were dissected with a bipolar grasper and the LigaSure system, and the vaginal wall was incised circumferentially with a monopolar coagulator. In cases of an adequate uterus size for vaginal removal ( $\leq 120 \mathrm{~g}$, as assessed with preoperative pelvic ultrasound), the uterus was removed through the vagina without morcellation. If morcellation was performed, the uterus was removed through manual morcellation within an endobag (LapBag; Sejong Medical, Seoul Korea) using a scalpel with an Octoport wound retractor. We routinely employed $15 \times 15-\mathrm{cm}$ polyurethane endobags. The endobag was opened intra-abdominally, and the uterine tissues were placed in the specimen bag with a grasper. In cases of uterine size $\geq 500 \mathrm{~g}$, we used a $20 \times 20-\mathrm{cm}$ endobag. Traction was applied to the uterus using towel clamps, and the uterine tissues were circumferentially cored with a scalpel. The entire manual morcellation was performed in the extracorporeal space to minimize intra-abdominal injury from a scalpel or spillage of uterine tissues. The detailed surgical technique of manual morcel- 


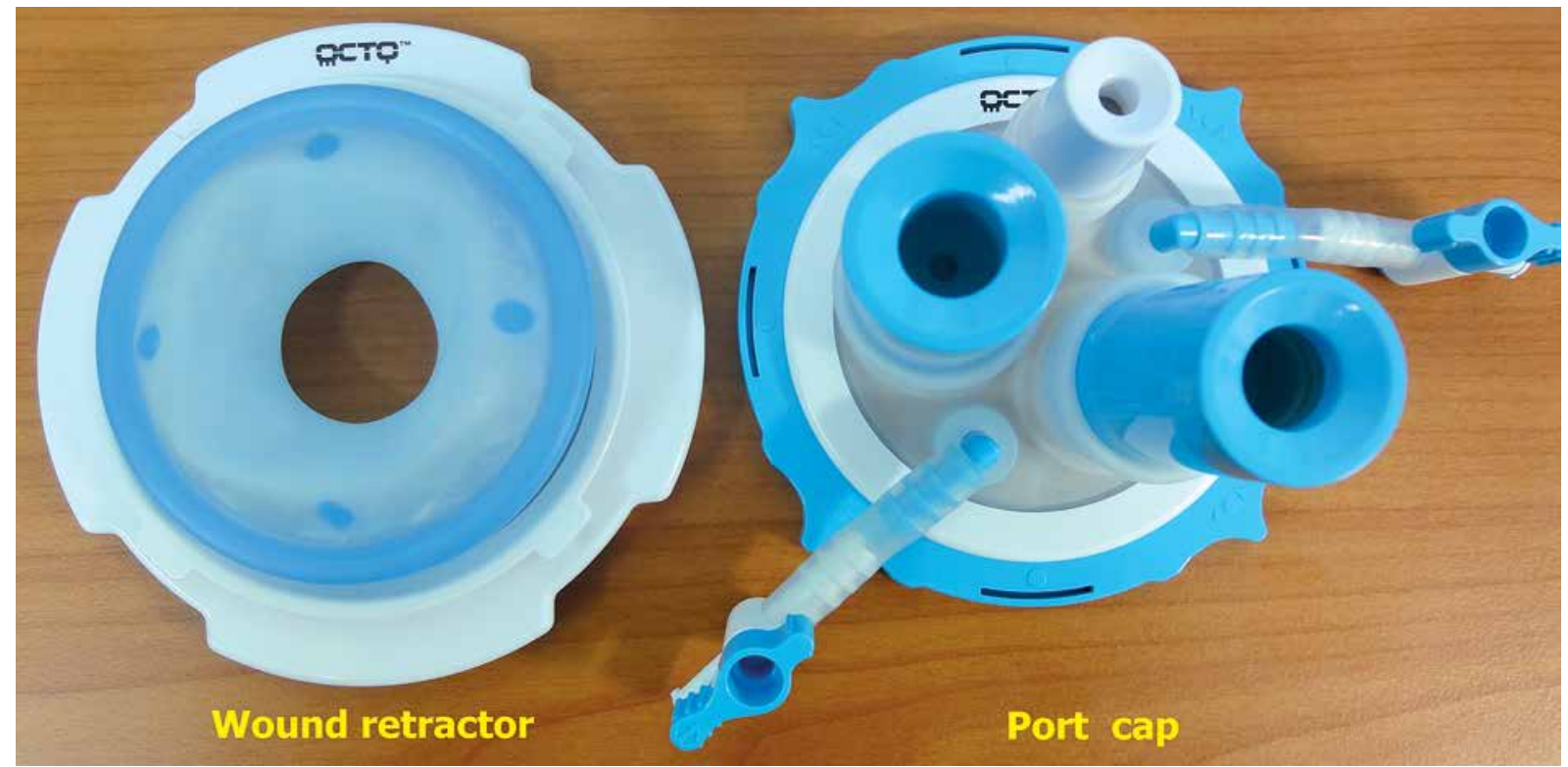

Photo 1. Octoport: wound retractor and detachable port cap

lation within an endobag has been described in our previous report [11].

In the barbed suture group, vaginal cuff closure was conducted laparoscopically using 23-cm 2-0 polyglyconate unidirectional barbed sutures with a 37-mm half-circle taper-point needle (V-Loc 90, Covidien). The first suture was locked with a loop at the right end of the vaginal cuff, and then a continuous suture was performed to the left end of the vaginal cuff and cut without tying a knot. In the traditional suture group, the vaginal cuff was closed laparoscopically with absorbable glyconate monofilament, using an extracorporeal sliding knot-tying technique [12]. The peritoneum and fascia of the umbilicus were closed with 2-0 Vicryl, and the skin was closed with a 4-0 Vicryl subcuticular continuous suture.

\section{Data collection and statistical analysis}

We analyzed the following parameters in all patients: age, body mass index, operative time, time to vaginal stump repair, blood loss, change in hemoglobin level, length of hospital stay, and intra- and postoperative complications. Statistical analysis was performed with SPSS version 21.0 software (SPSS, Chicago, IL, USA). Differences between subsets were evaluated with Student's $t$-test, and differences between proportions were compared with the $\chi^{2}$ test or Fisher's exact test. Regression analysis was used to evaluate the relationship between variables and consecutive cases. ANOVA was used to compare the median of each value among the groups. A $p$-value of $<0.05$ was considered statistically significant.

\section{Results}

Between August 2013 and June 2015, 85 consecutive patients underwent single-port TLH for benign or premalignant gynecological conditions at the Department of Gynecology in Kyungpook National University Medical Center in Daegu, Korea. The first 48 patients underwent single-port TLH with traditional interrupted sutures, and the next 37 patients underwent single-port TLH with absorbable unidirectional knotless barbed sutures for repair of the vaginal vault. No conversion or additional ports were needed in all cases. No difference existed between the two groups with respect to age, body mass index, history of abdominal surgery, or the incidence of additional surgical procedures. The indications for TLH were as follows: myoma and/or adenomyosis $(n=60)$, preinvasive cervical neoplasia $(n=22)$, borderline ovarian tumor $(n=3)$, and endometrial pathology $(n=2)$ (Table I).

The mean total operative time of the barbed suture group (57.8 $\pm 13.5 \mathrm{~min}$ ) was significantly shorter than that of the traditional suture group $(80.1 \pm 18.7 \mathrm{~min}$, $p<0.001$ ). Furthermore, the time to vaginal stump repair was significantly shorter in the barbed suture group (5.5 $\pm 1.7 \mathrm{~min}$ ) than in the traditional suture group 
(12.9 $\pm 3.5 \mathrm{~min}, p<0.001)$. The mean blood loss was $33.4 \pm 22.7 \mathrm{ml}$ in the traditional suture group and 31.1 $\pm 22.2 \mathrm{ml}$ in the barbed suture group $(p=0.634)$. There was no significant difference in the mean hemoglobin change between the two groups ( $1.1 \pm 0.8$ vs. $1.2 \pm 0.8$ $\mathrm{g} / \mathrm{dl}, p=0.542)$. The two groups were similar with re-

Table I. Patient characteristics

\begin{tabular}{|c|c|c|c|}
\hline Variables & Traditional suture $(n=48)$ & Barbed suture $(n=37)$ & $P$-value \\
\hline Age [years] & $47.3 \pm 6.2$ & $49.4 \pm 8.9$ & $0.211^{b}$ \\
\hline Body mass index $\left[\mathrm{kg} / \mathrm{m}^{2}\right]$ & $23.2 \pm 2.5$ & $24.8 \pm 4.2$ & $0.036^{b}$ \\
\hline \multicolumn{4}{|l|}{ Previous abdominal operations $(n)$ : } \\
\hline 0 & $32(66.7 \%)$ & $22(59.5 \%)$ & $0.572^{c}$ \\
\hline 1 & $9(18.7 \%)$ & $10(27.0 \%)$ & \\
\hline 2 & $2(4.2 \%)$ & $3(8.1 \%)$ & \\
\hline 3 & $5(10.4 \%)$ & $2(5.4 \%)$ & \\
\hline \multicolumn{4}{|l|}{ Indication for hysterectomy $(n)$ : } \\
\hline Myoma and/or adenomyosis & $32(66.7 \%)$ & $28(75.7 \%)$ & $0.681^{c}$ \\
\hline Preinvasive cervical neoplasia & $14(29.1 \%)$ & $8(21.6 \%)$ & \\
\hline Borderline ovarian tumor & $2(2.1 \%)$ & $1(2.7 \%)$ & \\
\hline Endometrial pathology & $2(2.1 \%)$ & $0(0 \%)$ & \\
\hline \multicolumn{4}{|l|}{ Surgical procedure: } \\
\hline TLH only & $33(68.7 \%)$ & $21(56.8 \%)$ & $0.255^{c}$ \\
\hline TLH with adnexal surgerya & $15(32.3 \%)$ & $16(43.2 \%)$ & \\
\hline
\end{tabular}

Data are presented as means \pm standard deviation or numbers (percentage of total). $T L H$-total laparoscopic hysterectomy. ${ }^{a} A d n e x a l$ surgery includes ovarian cystectomy and salpingo-oophorectomy, "bStudent's t-test, ' $\chi^{2}$ test.

Table II. Surgical outcomes

\begin{tabular}{|c|c|c|c|}
\hline Variables & Traditional suture $(n=48)$ & Barbed suture $(n=37)$ & $P$-value \\
\hline \multicolumn{4}{|l|}{ Operative time [min]: } \\
\hline Total operative time & $80.1 \pm 18.7$ & $57.8 \pm 13.5$ & $<0.001^{\mathrm{a}}$ \\
\hline Time to vaginal stump repair & $12.9 \pm 3.5$ & $5.5 \pm 1.7$ & $<0.001^{a}$ \\
\hline Blood loss [ml] & $33.4 \pm 22.7$ & $31.1 \pm 22.2$ & $0.634^{a}$ \\
\hline Hemoglobin change [g/dl] & $1.1 \pm 0.8$ & $1.2 \pm 0.8$ & $0.542^{\mathrm{a}}$ \\
\hline Length of hospital stay [days] & $3.2 \pm 0.7$ & $3.0 \pm 1.1$ & $0.307^{a}$ \\
\hline Weight of uterus [g] & $261.2 \pm 172.3$ & $233.9 \pm 149.6$ & $0.298^{a}$ \\
\hline Intraoperative complications ( $n$ ) & 1 & 0 & $1.000^{b}$ \\
\hline Bladder injury & 1 & 0 & \\
\hline Postoperative complications $(n)$ : & 4 & 3 & $1.000^{b}$ \\
\hline Umbilical discharge & 3 & 1 & \\
\hline Fever & 0 & 2 & \\
\hline Voiding difficulty & 1 & 0 & \\
\hline
\end{tabular}

Data are presented as mean \pm standard deviation or numbers. ${ }^{a}$ Student's $t$-test, ${ }^{b}$ Fisher's exact test. 
spect to the length of postoperative hospital stay (3.2 \pm 0.7 vs. $3.0 \pm 1.1$ days, $p=0.307$ ). The mean weight of the uterus was $261.2 \pm 172.3 \mathrm{~g}$ in the traditional suture group and $233.9 \pm 149.6 \mathrm{~g}$ in the barbed suture group ( $p=0.298)$. No intraoperative complications requiring treatment occurred in the barbed suture group; however, one case of bladder injury occurred in the traditional suture group. We laparoscopically repaired the injured bladder with 2-0 Vicryl without additional port insertion. There were no cases requiring blood transfusion in either group. Postoperative complications occurred in 5 (10.4\%) patients. There were 3 patients with umbilical discharge, 1 with voiding difficulty, and 1 with vaginal vault infection. There were 4 (10.8\%) cases of postoperative complications in the barbed suture group. Fever was identified in 2 patients, umbilical discharge in 1 patient, and vaginal vault bleeding in 1 patient (Table II).

To evaluate the learning curve of single-port TLH, the patients were divided into nine groups (groups
1-5: traditional suture groups, groups 6-9: barbed suture groups), and the operative time and blood loss were compared among the groups by ANOVA and multiple comparison tests. The total operative time and time for vaginal stump repair significantly decreased with increasing experience $(p<0.001)$. However, there was no significant difference among the groups with respect to blood loss ( $p=0.999)$. The operative time and time for vaginal stump repair were significantly reduced after the first 10 cases and thereafter remained the same in the traditional suture group. However, the total operative time and time for vagina stump repair were significantly reduced after using barbed sutures (Table III). In regression analysis, the operative time $\left(r^{2}=0.363\right.$, $p<0.001)$ and time to vaginal stump repair $\left(r^{2}=0.743, p<0.001\right)$ significantly decreased during the study period (Figure 1).

One month after the operation, vaginal granulation was identified in 2 cases $(p=1.000)$. However,

Table III. Surgical outcomes by sequence of operation

\begin{tabular}{|lcccccccccc|}
\hline Parameter & $\begin{array}{c}\text { Group 1 } \\
(1-10)\end{array}$ & $\begin{array}{c}\text { Group 2 } \\
(11-20)\end{array}$ & $\begin{array}{c}\text { Group 3 } \\
(21-30)\end{array}$ & $\begin{array}{c}\text { Group 4 } \\
(31-40)\end{array}$ & $\begin{array}{c}\text { Group 5 } \\
(41-48)\end{array}$ & $\begin{array}{c}\text { Group 6 } \\
(49-58)\end{array}$ & $\begin{array}{c}\text { Group 7 } \\
(59-68)\end{array}$ & $\begin{array}{c}\text { Group 8 } \\
(69-78)\end{array}$ & $\begin{array}{c}\text { Group 9 } \\
(79-85)\end{array}$ & $P$-value \\
\hline Time 1 [min] & $95.2 \pm 20.4$ & $72.3 \pm 11.0$ & $77.8 \pm 17.3$ & $72.9 \pm 11.4$ & $83.0 \pm 24.8$ & $63.7 \pm 15.1$ & $62.3 \pm 11.7$ & $51.5 \pm 7.0$ & $51.9 \pm 16.4$ & $<0.001^{\mathrm{a}}$ \\
\hline$T^{\mathrm{b}}$ & $\mathrm{a}$ & $\mathrm{b}, \mathrm{c}$ & $\mathrm{a}, \mathrm{b}$ & $\mathrm{b}, \mathrm{c}$ & $\mathrm{a}, \mathrm{b}$ & $\mathrm{b}, \mathrm{c}$ & $\mathrm{b}, \mathrm{c}$ & $\mathrm{c}$ & $\mathrm{c}$ & \\
\hline Time 2 [min] & $17.3 \pm 3.9$ & $13.1 \pm 2.6$ & $11.5 \pm 1.9$ & $10.9 \pm 1.9$ & $11.4 \pm 2.4$ & $6.6 \pm 1.4$ & $6.0 \pm 2.1$ & $4.4 \pm 0.8$ & $4.6 \pm 1.0$ & $<0.001^{\mathrm{a}}$ \\
\hline$T^{\mathrm{b}}$ & $\mathrm{a}$ & $\mathrm{b}$ & $\mathrm{b}$ & $\mathrm{b}$ & $\mathrm{b}$ & $\mathrm{c}$ & $\mathrm{c}$ & $\mathrm{c}$ & $\mathrm{c}$ & \\
\hline $\begin{array}{l}\text { Blood loss } \\
\text { [ml] }\end{array}$ & $36.0 \pm 15.1$ & $35.0 \pm 28.0$ & $30.0 \pm 27.5$ & $34.5 \pm 22.2$ & $31.3 \pm 23.0$ & $30.5 \pm 15.0$ & $32.0 \pm 25.7$ & $32.5 \pm 24.6$ & $28.6 \pm 26.7$ & $0.999^{\mathrm{a}}$ \\
\hline
\end{tabular}

Data are presented as means \pm standard deviation. ${ }^{a}$ Analysis of variance test, ${ }^{b}$ the same letters indicate non-significant differences between groups based on Tukey's multiple comparison test. Time 1 - total operative time; time 2 - time to vaginal stump repair.

A

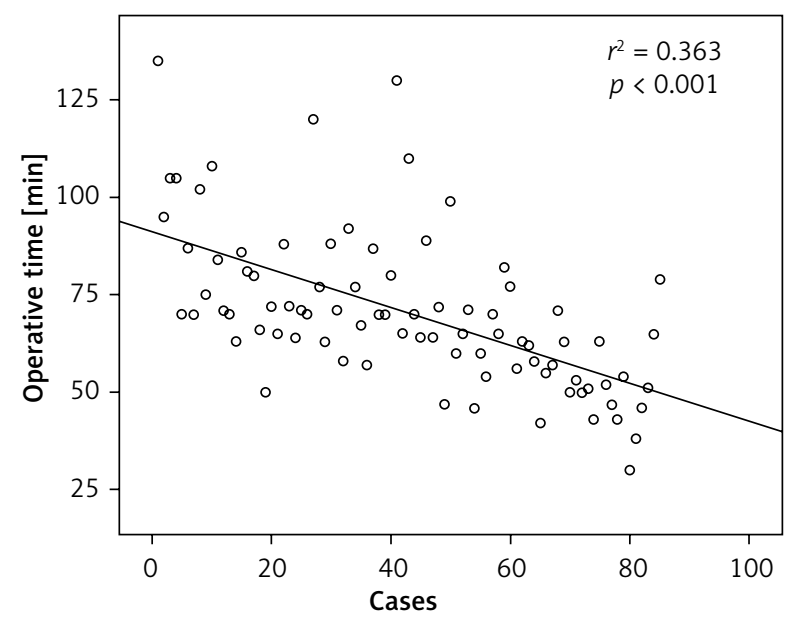

Figure 1. Regression analysis of the operative times
B

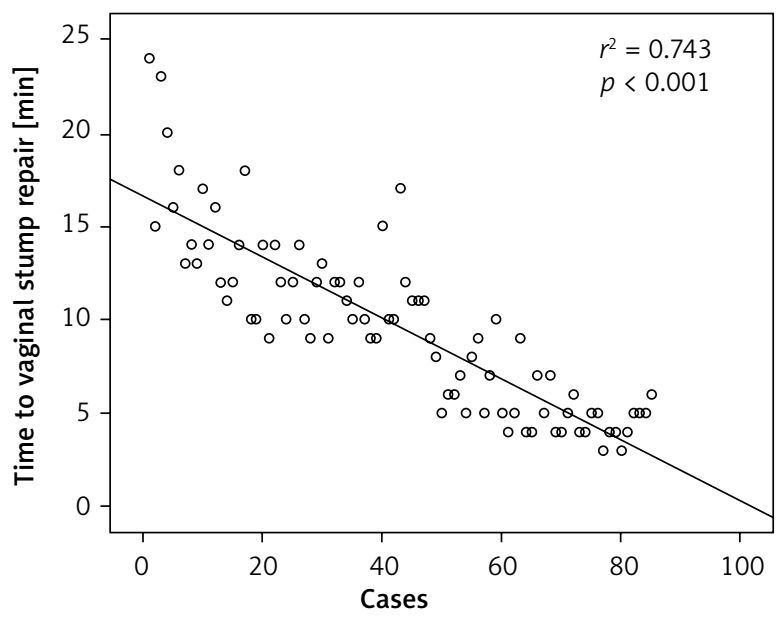


Table IV. Vaginal vault complications

\begin{tabular}{|lccccccccc|}
\hline Complication & \multicolumn{3}{c}{1 month } & \multicolumn{3}{c}{2 months } & \multicolumn{3}{c|}{5 months } \\
\cline { 2 - 10 } & $\mathrm{T}(n=48)$ & $\mathrm{B}(n=37)$ & $P$-value & $\mathrm{T}(n=48)$ & $\mathrm{B}(n=37)$ & $P$-value & $\mathrm{T}(n=48)$ & $\mathrm{B}(n=37)$ & $P$-value \\
\hline Granulation & $2(4.2 \%)$ & $1(2.7 \%)$ & $1.000^{\mathrm{a}}$ & $17(35.4 \%)$ & $1(2.7 \%)$ & $<0.001^{\mathrm{a}}$ & $6(12.5 \%)$ & $0(0 \%)$ & $0.033^{\mathrm{a}}$ \\
\hline Separation & $2(4.2 \%)$ & $1(2.7 \%)$ & $1.000^{\mathrm{a}}$ & 0 & 0 & $\mathrm{NA}$ & 0 & 0 & $\mathrm{NA}$ \\
\hline Infection & 0 & 0 & $\mathrm{NA}$ & $1(2.1 \%)$ & $0(0 \%)$ & $1.000^{\mathrm{a}}$ & 0 & 0 & $\mathrm{NA}$ \\
\hline
\end{tabular}

Data are presented as numbers (percentage of total). $T$-traditional suture, $B$ - barbed suture, $N A$ - not available. ${ }^{a}$ Fisher's exact test.

vaginal granulation occurred significantly more often in the traditional suture group (17 patients, 35.4\%) than in the barbed suture group (1 patient, $2.7 \%$; $p<0.001) 2$ months after the operation. Five months after the operation, vaginal granulation was identified in $6(12.5 \%)$ patients in the traditional suture group; however, no patients in the barbed suture group had vaginal granulation $(p=0.033)$. In cases of vaginal vault granulation, policresulen solution was applied to the granulation tissue. Vaginal vault separations were identified in 2 (4.2\%) patients in the traditional suture group and in $1(2.7 \%)$ patient in the traditional suture group at 1 month after the operation ( $p=1.000)$. Vaginal vault infection occurred in only 1 patient in the traditional suture group at 2 months after the operation (Table IV).

\section{Discussion}

A surgical knot yields the highest density of foreign body material in any given suture line, and the volume of a knot is directly related to the total amount of surrounding inflammatory reaction [13]. Previous studies have suggested that there is a higher incidence of vaginal vault complications after laparoscopic hysterectomy than after vaginal or abdominal hysterectomy [14, 15]. Postulated reasons cited to explain the higher incidence of vaginal vault complications in laparoscopic surgery include the use of electrosurgery to separate the specimen from the vagina and the quality of laparoscopic suture repair. Vaginal vault closure is one of the most difficult procedures during single-port TLH. The exact incidence of vaginal vault complications, including vaginal granulation, has not been reported yet. In this study, the vaginal vault complication rate was $37.5 \%$ in the group with single-port TLH with traditional interrupted vaginal sutures at 2 months after the operation. This incidence of vaginal vault complications is higher than that previously reported for multi-port
TLH $(0-5 \%)[3,4]$. The quality of the laparoscopic suture technique for vaginal vault closure in single-port TLH may especially contribute to the high incidence of vaginal vault complications. Moreover, surgical knots may contribute to the occurrence of vaginal vault complications in the traditional suture group during single-port TLH. In this study, vaginal vault complications, especially vaginal granulation, were dramatically reduced with the use of barbed sutures. Because barbed sutures self-anchor at every $1 \mathrm{~mm}$ of tissue and no knots are required, these sutures may yield more consistent wound apposition.

For laparoscopic surgery to be advantageous, the surgeon must be proficient in the surgical technique. Defining the learning curve for laparoscopic surgery is necessary for guiding the implementation of this surgery in the standard education of gynecologists. Previous studies have suggested that surgeons need to perform 25 cases to complete the learning curve for multi-port TLH $[16,17]$. However, data on the learning curve for single-port TLH are limited. Paek et al. demonstrated that proficiency in single-port TLH was achieved after 40 cases [18]. In this study, a plateau in the learning curve for single-port TLH was reached after the first 10 cases. Moreover, the total operative time and time for vaginal stump repair were significantly reduced after completing the learning curve when using barbed sutures.

The major limitations of the present study are that it was non-randomized, and the comparisons were made during two different study periods. It is possible that the surgical technique improved as the study progressed, which could have potentially affected the results.

Despite these limitations, the present study demonstrated that the use of barbed sutures overcame the learning curve of traditional interrupted sutures for single-port TLH. Moreover, details of the vaginal vault complication rate after single-port TLH were provided. 


\section{Conclusions}

The operative time and time for vaginal stump suturing were significantly reduced with experience in single-port TLH. Moreover, barbed sutures may contribute to overcoming the learning curve of single-port TLH. The frequency of vaginal stump complications, especially vaginal granulation, was significantly lower in the barbed suture group than in the traditional suture group. Barbed sutures may help overcome the surgical difficulty and vaginal cuff complications of single-port TLH.

\section{Conflict of interest}

The authors declare no conflict of interest.

\section{References}

1. Johnson N, Barlow D, Lethaby A, et al. Surgical approach to hys terectomy for benign gynaecological disease. Cochrane Database Syst Rev 2006; 19: CD003677.

2. Wang T, Chong GO, Park NY, et al. Comparison study of single-port (Octoport ${ }^{\mathrm{TM}}$ ) and four-port total laparoscopic hysterectomy. Eur J Obstet Gynecol Reprod Biol 2012; 161: 215-8.

3. O'Hanlan KA, Dibble SL, Garnier AC, et al. Total laparoscopic hysterectomy: technique and complications of 830 cases. JSLS 2007; 11: 45-53.

4. Medina BC, Giraldo CH, Riaño G, et al. Barbed suture for vaginal cuff closure in laparoscopic hysterectomy. JSLS 2014; 18: 83-8.

5. Berman ML, Grosen EA. A new method of continuous vaginal cuff closure at abdominal hysterectomy. Obstet Gynecol 1994; 84: 478-80.

6. Beresford JM, Moher D. A prospective comparison of abdominal hysterectomy using absorbable staples. Surg Gynecol Obstet 1993; 176: 555-8.

7. Saropala N, Ingsirorat C. Conservative treatment of vaginal vault granulation tissue following total abdominal hysterectomy. Int J Gynaecol Obstet 1998; 62: 55-8.

8. Song T, Lee SH. Barbed suture vs traditional suture in single-port total laparoscopic hysterectomy. J Minim Invasive Gynecol 2014; 21: 825-9.

9. Siedhoff MT, Yunker AC, Steege JF. Decreased incidence of vaginal cuff dehiscence after laparoscopic closure with bidirectional barbed suture. J Minim Invasive Gynecol 2011; 18: 218-23.

10. Rettenmaier MA, Abaid LN, Brown JV 3rd, et al. Dramatically reduced incidence of vaginal cuff dehiscence in gynecologic patients undergoing endoscopic closure with barbed sutures: a retrospective cohort study. Int I Surg 2015; 19: 27-30.

11. Chong GO, Lee YH, Hong DG, et al. Robotic hysterectomy or myomectomy without power morcellation: a single-port assisted three-incision technique with manual morcellation. Int J Med Robot 2016; 12: 483-9.

12. Lee YH, Kim MJ, Chong GO, et al. YS knot: a new technique for a tension-controlled slip knot using a trocar. Obstet Gynecol Sci 2015; 58: 171-4.

13. Greenberg JA, Goldman RH. Barbed suture: a review of the technology and clinical uses in obstetrics and gynecology. Rev Obstet Gynecol 2013; 6: 107-15.

14. Hur HC, Donnellan N, Mansuria S, et al. Vaginal cuff dehiscence after different modes of hysterectomy. Obstet Gynecol 2011; 118: 794-801.

15. Agdi M, Al-Ghafri W, Antolin R, et al. Vaginal vault dehiscence after hysterectomy. J Minim Invasive Gynecol 2009; 16: 313-7.

16. Garry R, Fountain J, Mason S, et al. The eVALuate study: two parallel randomised trials, one comparing laparoscopic with abdominal hysterectomy, the other comparing laparoscopic with vaginal hysterectomy. BMJ 2004; 328: 129.

17. Twijnstra AR, Blikkendaal MD, Kolkman W, et al. Implementation of laparoscopic hysterectomy: maintenance of skills after a mentorship program. Gynecol Obstet Invest 2010; 70: 173-8.

18. Paek J, Kim SW, Lee SH, et al. Learning curve and surgical outcome for single-port access total laparoscopic hysterectomy in 100 consecutive cases. Gynecol Obstet Invest 2011; 72: 227-33.

Received: 16.03.2017, accepted: 20.05.2017. 